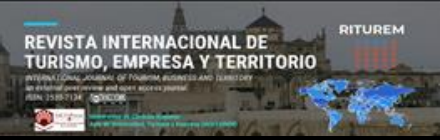

Cita bibliográfica: Cruz Bermúdez, L.D. y González Damián, A. (2020). Desarrollo turístico y sostenibilidad en la comunidad de Caibarién (Cuba). Revista Internacional de Turismo, Empresa y Territorio, $4 \quad$ (2), 103-127. https://doi.org/10.21071/riturem.v4i2.12876

\title{
Desarrollo turístico y sostenibilidad en la comunidad de Caibarién (Cuba)
}

\section{Tourism Development and Sustainability in the community of Caibarién, Cuba}

\author{
Luis Daniel Cruz Bermúdez ${ }^{1}$
}

\author{
Alfonso González Damián²
}

\begin{abstract}
Resumen
El presente artículo surge de la necesidad de desvelar la influencia del desarrollo turístico en las dimensiones del desarrollo sostenible de la comunidad de Caibarién (Cuba). La información se obtuvo mediante revisión documental y entrevistas semi estructuradas. Los fundamentos teóricos y metodológicos que soportan el tratamiento de este trabajo se estructuran a partir de la producción científica relativa a los temas del desarrollo turístico y el turismo sostenible. Los principales resultados mostraron que la estrategia de desarrollo de Gaviota S.A en los Cayos de Villa Clara, influye indirectamente en la sostenibilidad de la comunidad de Caibarién, lo cual coincide con lo que plantea la literatura académica y presenta su pertinencia también para el caso de Cuba, cuya organización socioeconómica y política se distancia del paradigma neoliberal global. Si bien existen algunas pautas que muestran una tendencia hacia el desarrollo sostenible, aún se identifican aspectos negativos en el modelo de desarrollo turístico que habrán de ser considerados tanto en futuras investigaciones como en sus implicaciones prácticas en la industria turística de Cuba y de otras latitudes.
\end{abstract}

Palabras clave: Desarrollo turístico; Sostenibilidad; Dimensiones social, económica y ambiental; Cuba.

\begin{abstract}
This article arises from the need to reveal the influence of tourism development on the dimensions of sustainable development in the community of Caibarién, Cuba. The information was obtained through documentary review and semi-structured interviews. The theoretical and methodological foundations that support the treatment of the subject are structured from the scientific production related to the topics of tourism development and sustainable tourism. The main results showed that the development strategy of Gaviota SA in the Villa Clara Keys, indirectly influences the sustainability of the Caibarién community, which coincides with what is stated in the academic literature and is also relevant for the case of Cuba, whose socio-economic and political organization distances itself from the global neoliberal paradigm. Although there are elements that show a trend towards sustainable development, negative aspects were still identified as a consequence of the presence of tourism development that will have to be considered both in future research and in its practical implications in the tourism industry of the Island and of other latitudes.
\end{abstract}

\footnotetext{
${ }^{1}$ Licenciado en Turismo. Maestría en Gestión Sustentable del Turismo. Universidad de Quintana Roo, Unidad Cozumel. México. Email: luisdanielcruzbermudez@gmail.com.*

${ }^{2}$ Doctor en Ciencias Sociales. Profesor-investigador. Universidad de Quintana Roo, Unidad Cozumel. México. Email: alfonso.gonzalezdamian@gmail.com. Orcid.org/0000-0003-4396-0100.
} 
Keywords: Tourism development; Sustainability; Social, economic and environmental dimensions; Cuba.

\section{Introducción}

La industria del turismo, además de aportar beneficios económicos, crea oportunidades de empleo, contribuye a la economía local (Andriotis \& Vaughan, 2003; Lankford \& Howard, 1994; Nunkoo y Ramkissoon, 2010) y tiene el potencial de contribuir al mejoramiento de la economía y el bienestar y calidad de vida de los miembros de la comunidad local (Andereck, Valentine, Knopf, \& Vogt, 2005). Según Perdue, Tyrrell y Uysal (2010) el valor en el turismo ha pasado a centrarse más en medidas no económicas y a las formas abstractas de valor como el bienestar, la sensación de bienestar y la sostenibilidad. Por lo tanto, las estrategias de desarrollo turístico no solo se deben enfocar en los beneficios económicos sino también en los sociales y ambientales, posibilitando el desarrollo enfatizado en las comunidades que involucran, logrando manifestar un beneficio en las mismas mediante un enfoque de desarrollo sostenible.

Sin embargo, los impactos del turismo no siempre son beneficiosos para el desarrollo sostenible. Se ha culpado al turismo por el aumento en el costo de la vida para la población anfitriona que reside en las zonas de importante afluencia turística (Lee \& Back, 2006), por una distribución desigual de los ingresos (Alam \& Paramati, 2016), un empleo poco cualificado y mal pagado (Davidson \& Sahli, 2015), la degradación de los recursos naturales y culturales (Bowers, 2016), crimen (Ap, 1992; Lee \& Back, 2006), y un bajo grado de empoderamiento de la sociedades locales (Hatipoglu, Alvarez, \& Ertuna, 2016). Fyall y Garrod (1998) identificaron que, si bien el sector del turismo es una de las industrias más grandes del mundo, no ha logrado incorporar efectivamente prácticas sostenibles de manera sustantiva y significativa.

Por lo tanto, las entidades que manejan la actividad turística tienen la labor de fomentar un desarrollo turístico sostenible para así lograr un equilibrio entre la industria y las comunidades incidiendo, de alguna manera, en el bienestar y la mejora de todos. Desde los preceptos del desarrollo sostenible el turismo puede contribuir a la calidad de vida de las comunidades, si se lleva a cabo desde este paradigma, debido a que ofrece oportunidades para que los residentes aprecien y respeten la cultura local, aumentando así la sostenibilidad del socio-ecosistema (Ruiz-Ballesteros, 2011), contribuyendo al desarrollo de la comunidad y apoyando así la sostenibilidad de la comunidad (Lee \& Jan, 2019). Además, los recursos naturales únicos aumentan la conciencia ambiental de los residentes, lo que lleva a una mayor protección ambiental en un intento por brindar experiencias de recreación de alta calidad (Lee, Jan \& Yang, 2013; Lee, Jan, Tseng, \& Lin, 2018).

Cuba está situada dentro de los primeros países en el Caribe en donde el turismo es parte primordial en su economía, regido por el desarrollo socioeconómico que se ha venido produciendo en los últimos años como alternativa al modelo neoliberal existente en el mundo. El desarrollo en Cuba está sustentado en la ideología de la Revolución Cubana que, al menos desde el punto de vista del discurso teórico oficial, se ha de basar en la equidad, la justicia social y el acceso a la educación masiva de calidad. (PCC, 2017). Esto implica que el desarrollo social y la igualdad económica deben explícitamente controlar todas las empresas cubanas, por lo que el Estado promueve, a través de las regulaciones, el desarrollo de la población a través del trabajo. La constitución cubana establece, además, la protección del medio ambiente y su vinculación con el desarrollo sostenible (PCC, 2019).

Políticamente Cuba como país soberano establece un sistema que pretende oponerse a las bases del capitalismo, por lo que presenta características que la hacen única, respecto al resto 
de las naciones a nivel global como son la existencia de un solo partido Político y la centralización del poder, el sistema económico de propiedad estatal, la sociedad no consumista e ideológicamente comprometida con el Gobierno y el turismo como principal estrategia de desarrollo económico basado en asociaciones mercantiles (PCC, 2019). Todo lo anterior evidencia la importancia del papel de las empresas en la gestión de dicho desarrollo para lograr una efectividad relevante en la implementación de proyectos que beneficien a la comunidad en general.

Por su parte, la comunidad de Caibarién presenta una situación de desarrollo aún desequilibrado, la cual, según estudios de González (2015) se basa en insuficiente infraestructura técnica (abasto de agua, solución de residuales, drenaje, electricidad, etc.), contaminación marina por residuales domésticos e industriales y el manejo inadecuado del litoral, insuficiente red vial y problemas de comunicación interna (González, 2015). Sin embargo, a pesar de que el turismo desarrollado en el territorio parece ser económicamente rentable para la comunidad de Caibarién debido a que los ingresos por turismo en 2018 se calcularon en 7.119,504,6 pesos (ONEI, 2019a), y el alto por ciento de representatividad laboral en la empresa donde aproximadamente el $16 \%$ de la población total labora en esta (ONEI, 2019a), no se conoce cuál es su influencia real en la sostenibilidad local de las personas que residen en Caibarién. Por lo tanto, el objetivo del presente artículo es analizar la incidencia del desarrollo turístico de la región en la sostenibilidad local de Caibarién.

\section{La concepción del desarrollo turístico sostenible}

Es comúnmente aceptado que la sostenibilidad y el turismo están interrelacionados. La efectividad de la actividad turística para facilitar y respaldar la política de calidad de vida, como la reducción de la pobreza en las comunidades de acogida, la revitalización del patrimonio y la cultura de la comunidad, la preservación y protección de los recursos culturales y naturales, y la sostenibilidad es una agenda de investigación cada vez más importante. El objetivo a largo plazo es proporcionar experiencias turísticas de calidad, evitar la explotación excesiva de los recursos y promover la conservación para las generaciones futuras. Por lo tanto, se considera un agente de transformación social con posibilidades de incrementar las oportunidades de empleo y la calidad de vida de los habitantes. (Melgar, 2004).

La Organización Mundial de Turismo (OMT, 2000) define el turismo sostenible como aquel que pretende satisfacer las necesidades de los turistas, así como de los destinos turísticos protegiendo e incrementando las oportunidades a futuro. Esto implica gestionar los recursos de manera que las necesidades económicas, sociales y estéticas puedan ser satisfechas mientras se mantiene la identidad cultural, los procesos ecológicos esenciales, la diversidad biológica y los sistemas de vida (Pérez de las Heras, 2004). Por lo tanto, el desarrollo turístico sostenible pretende minimizar los impactos negativos ambientales y culturales, maximizar la satisfacción del turista e incrementar el desarrollo económico a largo plazo. Sin embargo, es importante señalar que el turismo sostenible no es un producto, sino una base filosófica necesaria y una forma de hacer turismo de principios éticos y responsables para apoyar y proporcionar una orientación para desarrollar el turismo en los destinos y hacer buen uso de los recursos naturales y culturales que en este se albergan (Rivera, 2012; Rivera Rodríguez, 2012; Cardoso, 2014).

El desarrollo turístico es una herramienta que posibilita la acción positiva en cada uno de los ODS, siempre y cuando su gestión sea llevada a cabo de manera que tenga en cuenta los preceptos de cada objetivo en función de mitigar los problemas sociales, cumplir con los objetivos de la empresa y favorecer el bienestar de la humanidad. Por lo tanto, la sostenibilidad 
debe ser un eje primordial en la planificación turística y la gestión empresarial, debido a que a través de esta se reducirán los impactos negativos del turismo y aumentarán los beneficios para todos los actores involucrados en la industria en conjunto con la conservación de la vida en el planeta.

La aplicación de las dimensiones de la sostenibilidad al turismo ha estado influenciada por la contradicción existente entre su amplia difusión y las limitaciones de los avances alcanzados. La repercusión de la sostenibilidad en el turismo ha posibilitado que este paradigma agrupe el debate en torno a las implicaciones del turismo para el desarrollo y sus efectos ambientales, socioculturales y económicos. (Vera-Rebollo, 2001).

El desarrollo turístico sostenible ha de ser responsable ecológicamente y a largo plazo, viable económicamente y equitativo desde una perspectiva estética y social para la comunidad receptora (OMT, 1997). Por lo tanto, el turismo sostenible es un modelo de desarrollo económico diseñado para mejorar la calidad de vida de la población local, proveer mayor calidad de las experiencias para los visitantes, mantener la calidad del medio ambiente de la cual depende tanto la población local como los visitantes, la consecución de mayores niveles de rentabilidad económica de la actividad turística para los residentes locales y asegurar la obtención de beneficios por parte de los empresarios turísticos (Pérez de las Heras, 2004). Además, permite disfrutar de un positivo intercambio de experiencias entre residentes y visitantes, donde la relación entre el turista y la comunidad es justa, los beneficios de la actividad son repartida de forma equitativa y donde los visitantes tienen una actitud verdaderamente participativa en su experiencia de viaje (Asociación de Monitores Medioambientales Almijara, 2008). Sin embargo, aún existen modelos de emprendimiento y desarrollo del turismo ortodoxos que están sesgados hacia un enfoque economicista a corto plazo que debilita los beneficios previstos de la industria, especialmente para las comunidades anfitrionas (Pollock, 2015).

Por otro lado, las empresas que intentan llevar a cabo un desarrollo turístico sostenible y que abogan por un turismo socialmente responsable, enfrentan desafíos relacionados con el negocio, como la falta de rentabilidad y problemas de marketing (Laeis \& Lemke, 2016). Además, muchos de los negocios responsables son establecidos por personas externas, los cuales pueden aplicar programas de capacitación inadecuados, y crear una excesiva dependencia financiera externa, imposibilitando el desarrollo centrado en la comunidad (Peredo y Wurzelmann, 2015). Por último, se puede decir que, sin su propósito social, el emprendimiento social sigue de alguna manera una agenda capitalista. (Porter, Orams y Lück, 2015). Esto conlleva, por un lado, a una invitación a otras empresas externas a incluirse en la cadena de suministros del turismo, imposibilitando el desarrollo de los negocios locales y, por otro lado, las estrategias de la empresa pueden estar basadas en la promoción de productos sostenibles y socialmente responsables pero su objetivo principal es seguir obteniendo ingresos del mercado y lograr un posicionamiento efectivo de acuerdo con las nuevas necesidades de los consumidores.

La importancia del turismo sostenible radica en el potencial para crear valor económico, ambiental y social fomentando la participación de la sociedad y así crear una industria turística más inclusiva. (Aquino, Lück y Schänzel, 2018). Como “empresas sostenibles” primero se deben comprender las necesidades de la región al asociarse y aprender de las comunidades y así aumentar la probabilidad de que estas tengan una participación significativa en el turismo, y que sus necesidades y aspiraciones sean escuchadas y actuadas por los gobiernos locales que usualmente tienen el poder de implementar iniciativas de desarrollo turístico logrando así una influencia positiva en la calidad de vida de todos los residentes. Por lo tanto, para lograr la sostenibilidad, los gestores necesitan un mayor apoyo de todas las partes interesadas, así como 
de los científicos y las organizaciones no gubernamentales (ONG), y así lograr una gestión eficiente del desarrollo y proveer mayores beneficios a las comunidades locales.

\section{Caracterización del área de estudio: Polo turístico Cayos de Villa Clara y su relación con Caibarién.}

Los Cayos de Villa Clara están enclavados dentro del archipiélago de Sabana- Camagüey, en la zona costera de las provincias de Matanzas, Villa Clara, Sancti Spíritus, Ciego de Ávila y Camaguiey. Se encuentran en esta zona un total de 35 espacios protegidos. Desde el punto de vista administrativo pertenecen al municipio Caibarién, de la provincia cubana de Villa Clara (Figura 1).

La Cayería Norte de Villa Clara y oficialmente Cayería de Villa Clara o Cayos de Villa Clara, es un espacio insular perteneciente a la provincia cubana de Villa Clara formada por los cayos de Santa María, Ensenachos y Las Brujas de su sección noreste, los cuales poseen una infraestructura turística de más de 10.000 habitaciones, siendo uno de los principales polos turísticos del país (Gaviota, 2019). Existen en la región un total de 22 hoteles y dos más en proceso de construcción, pertenecientes al Estado en asociación con empresas extranjeras que operan bajo el régimen "todo incluido" a excepción de Villa Las Brujas. Además, cuenta con 6 instalaciones extra-hoteleras, y un aeropuerto de pequeña escala (Gaviota, 2019).

Figura 1: Ubicación Cayos de Villa Clara.

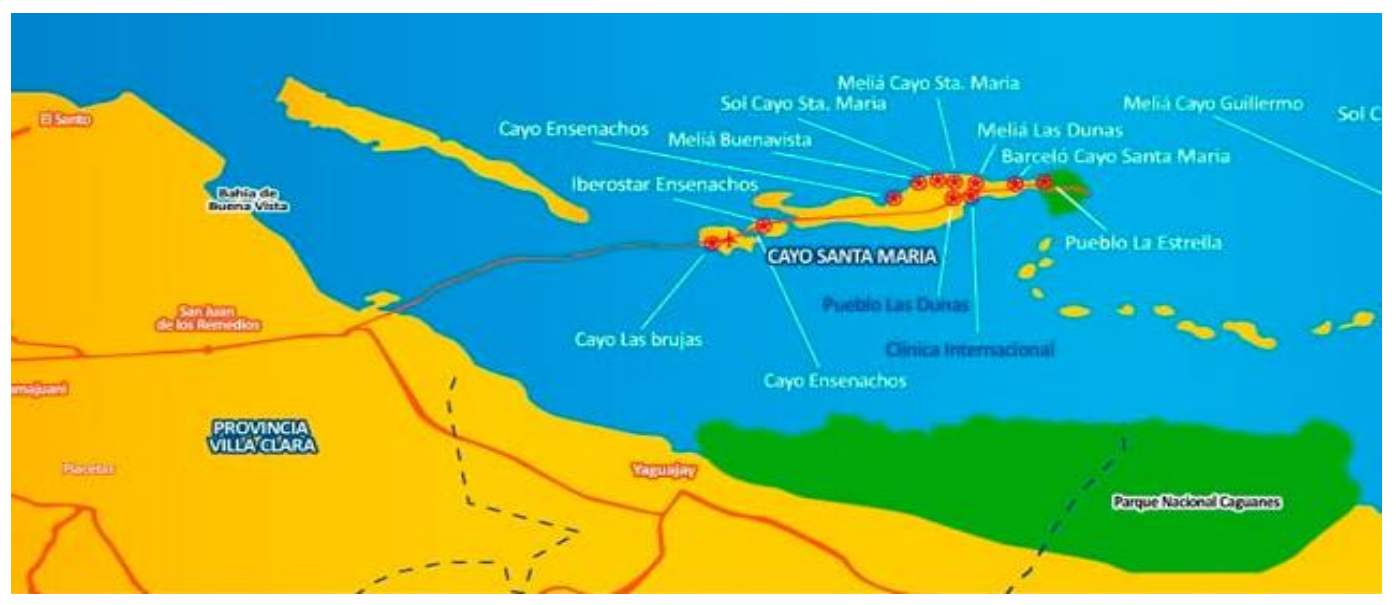

Fuente: http://www.agencia-viajes-lima.com/mapa_cayos.htm

Dicho sistema de cayos se encuentra unido a la isla de Cuba por una calzada de 48 kilómetros (pedraplén) que mereció el premio internacional "Puente de Alcántara" en atención al especial cuidado del medio ambiente en su trazado y ejecución (Mayoral, 2001). La única pista de aterrizaje es el Aeropuerto Internacional de Villa las Brujas, al que pueden llegar aeronaves internacionales de pequeño y mediano porte. En cuanto al alojamiento, es comercialmente identificado como un destino "todo incluido". Cayos de Villa Clara cuenta en la actualidad con más de 12000 habitaciones, agrupadas en 19 hoteles 5 estrellas, un hotel 4 
estrellas y una villa 3 estrellas, mientras que se prevé la apertura de dos nuevos hoteles (MINTUR, 2018).

La ciudad de Caibarién fue fundada el 26 de octubre de 1832, aunque desde años anteriores funcionaba como puerto marítimo. Actualmente contiene una población de 39.946 habitantes (ONEI, 2015). Se encuentra situada en la costa noreste de la provincia de Villa Clara. Emplazada frente a la ensenada de su nombre en el extremo sureste de la bahía de San Juan de los Remedios, en la carretera "Circuito Norte", dista 49 km de Santa Clara, capital provincial y a $41 \mathrm{~km}$ de Cayos de Villa Clara (Figura 2). La tendencia demográfica es actualmente de crecimiento migratorio positivo y de expansión urbana como consecuencia de la atracción que genera el desarrollo turístico geográficamente próximo. En este nuevo contexto la ciudad se sitúa como el asentamiento de población más cercano al polo turístico Cayos de Villa Clara, convirtiéndose en fuente fundamental de fuerza laboral directa e indirecta $\mathrm{y}$, al mismo tiempo, dispone de una oferta cultural complementaria al producto de sol y playa, por lo que la interacción turista-anfitrión tiende a incrementarse.

Figura 2: Ubicación de Caibarién.

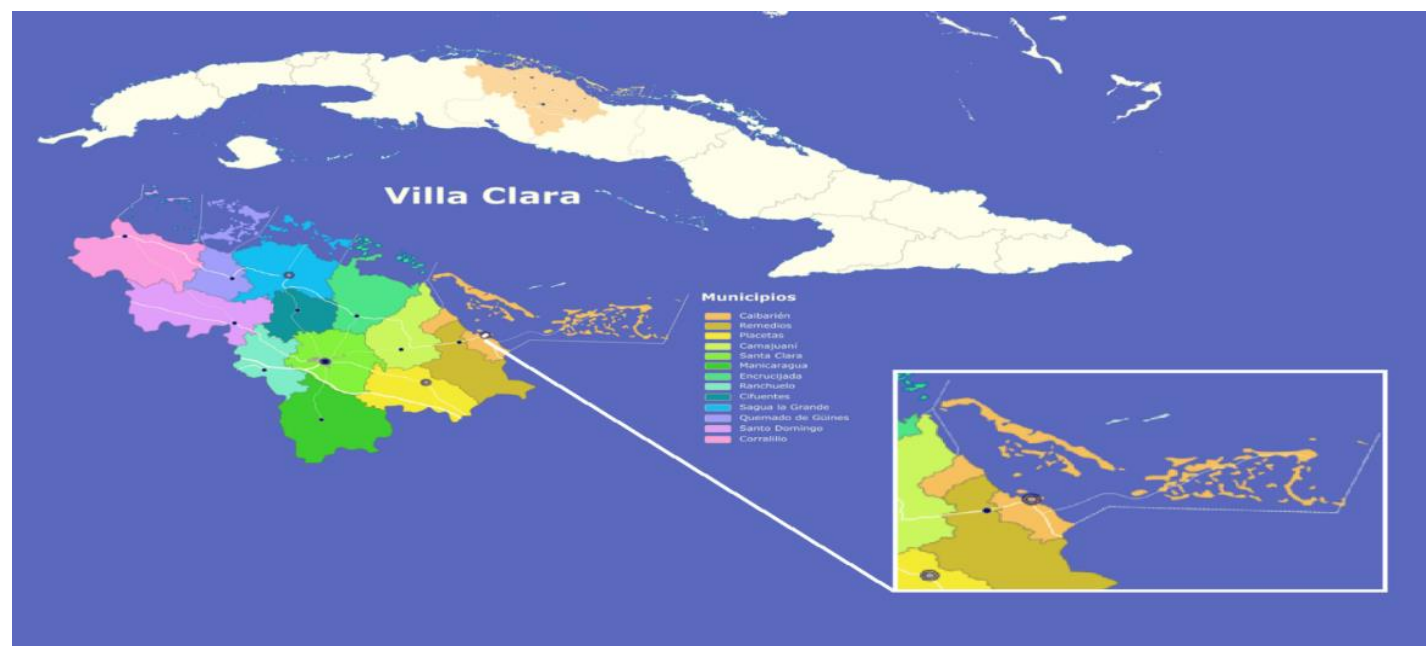

Fuente: http://www.ecured.cu

Antes del comienzo del desarrollo del turismo en 1995 y de concluirse la obra del pedraplén Caibarién-Cayo Santa María con $48 \mathrm{Km}$ de extensión como vial de acceso, la principal actividad económica de la región era la pesca. Posteriormente, bajo la dirección del Estado comienza a evidenciarse el apoyo al turismo como la actividad fundamental para el municipio. Dentro de la ciudad se origina un corredor turístico en el tránsito vehicular desdehacia el polo Cayos de Villa Clara, así como con varios corredores peatonales que orientan la movilidad turística siguiendo las rutas urbanas que conectan los atractivos principales, el malecón costero y el flujo hacia las playas locales. Al contrario de la amplia oferta de instalaciones de ocio que posee la Cayería norte, en la región poblada de Caibarién, se localizan de forma puntual instalaciones recreativas, principalmente en ejes viales y determinados sectores, pero en pobres condiciones por lo que cuenta con una base material muy pobre para la recreación, brindando muy pocas ofertas para la población y para el turismo internacional. La infraestructura de apoyo de la que dispone el municipio tiene una mayor representatividad en la cayería noreste, donde existen burós de venta de varias agencias de viajes de la provincia y agencias transportistas para el turismo. 
Según el Instituto Provincial de Planificación Física de Villa Clara, la ciudad de Caibarién posee 259 instalaciones dedicadas a la prestación de servicios, en los que predominan los del Comercio Alimenticio y de Salud Pública con 76 y 47 instalaciones respectivamente, que representan el $47.5 \%$ del total, seguidas de las Gastronómicas con 39 y Educacionales con 25 instalaciones. El resto de las redes de servicios objeto de análisis son Deportes, Servicios Personales y de Reparación, Comercio Industrial y Cultural.

Los principales impactos del turismo son: su contribución como fuente de empleo e ingresos, incentivo al desarrollo de la infraestructura y al cuidado del medio ambiente, así como diferencias económicas, deterioro de valores sociales, cambios en el comportamiento ideológico y estilos de vida, un éxodo del personal de otros sectores hacia la esfera turística, reasentamientos urbanos y crecimiento poblacional y contrastes en la imagen paisajística urbana (González, 2011; Herrera \& Montero, 2009).

\section{Metodología y herramientas de trabajo.}

Para alcanzar los objetivos planteados en este trabajo, se decidió obtener información procedente de entidades encargadas de gestionar a nivel regional el turismo en Cayos de Villa Clara, atendiendo a las temáticas ambiental, social y económica, identificables como las tres dimensiones de la sostenibilidad (Purvis, et al., 2019), al considerarse de manera simultánea y en equilibrio. La información se buscó principalmente en formato documental, con el objeto de que permitiera realizar sobre este material un análisis más más detallado y reiterado. No obstante, fue preciso complementar el material con tres entrevistas semiestructuradas y en profundidad (ver guía utilizada en el anexo). El conjunto del material recabado responde a un código de anonimato, ética y licitud, tanto de los informantes como de las entidades que directamente proporcionaron el material. Por tal razón, no se proporcionan aquí mayores detalles sobre su identidad, además de que, en el caso de la información obtenida en las entrevistas, se acordó que sólo se revisaría la información junto con los responsables de su custodia y/generación, estableciéndose la prohibición de fotografías, copias directas o algún otro tipo de duplicado. Los datos obtenidos fueron revisados por cada órgano correspondiente y las conclusiones acotadas en esta investigación responden al espectro amplio de la industria turística del territorio, por lo que no se evidencian datos estratégicos internos y particulares de las organizaciones afectadas.

Las información así obtenida se organizó y clasificó conforme al marco de los indicadores mundiales para los Objetivos de Desarrollo Sostenible (ONU, 2018) y metas de la Agenda 2030 (Colglazier, 2015), de manera que se pudieran describir e identificar las acciones de las empresas en la región Caibarién - Cayos de Villa Clara y su impacto en las dimensiones económica, social y ambiental y considerando, en este sentido, el contexto en el que se ha desarrollado desde sus inicios en 1995 hasta el momento de la recopilación de información, que fue realizada en agosto de 2019. La revisión documental y la información proveniente de las entrevistas permitió, tras una revisión minuciosa, identificar aspectos directamente vinculados con las tres dimensiones de la sostenibilidad, que sirven además como argumentos para comprender el impacto del desarrollo turístico en tales dimensiones a lo largo de 24 años en el área de estudio. Los resultados de esta aproximación analítica se presentan a continuación.

\section{Resultados}

\subsection{Dimensión ambiental.}


Las expectativas de las empresas turísticas en cuanto a desarrollo sostenible, transparencia y responsabilidad han evolucionado dentro del contexto de requisitos legales cada vez más estrictos y las presiones crecientes con relación a la contaminación del medio ambiente y el cambio climático (MINTUR, 2016). El marco organizativo en la región se basa en la Estrategia Ambiental Nacional y las proyecciones actuales de la gestión ambiental en la República de Cuba. Esta estrategia se basa en los instrumentos nacionales de gestión ambiental:

-La Ley número 81/1997 “Del Medio Ambiente”, su regulación complementaria y demás regulaciones legales destinadas a proteger el medio ambiente.

-El ordenamiento ambiental: Considera íntegramente, los aspectos ambientales y su vínculo con los factores económicos, demográficos y sociales, a fin de alcanzar la máxima armonía posible.

-La licencia Ambiental: Licencia otorgada por el Ministerio de Ciencia Tecnología y Medio Ambiente de conformidad con lo que estipule, a toda actividad susceptible de producir efectos significativos sobre el medio ambiente o que requiera de un debido control a los efectos del cumplimiento de lo establecido por la legislación ambiental vigente.

-La evaluación de impacto ambiental.

-El Sistema Nacional de Información Ambiental.

-El Sistema de Inspección Ambiental Estatal.

-La Educación Ambiental.

-La investigación científica y la innovación tecnológica. (MINTUR, 2016)

La gestión empresarial está basada en la NC ISO 14001:2015 como instrumento regulador para establecer las acciones encaminadas a la protección, conservación y control del medio ambiente. Esta norma es una transposición y adaptación del país a las Normas ISO Internacionales, las cuales aprueban su uso a nivel nacional. Los requisitos de la NC ISO 14001:2015 se consideran desde una perspectiva sistemática u holística, por lo que se establece una interrelación con requisitos de otros sistemas integrados de gestión (calidad, seguridad y salud en el trabajo y control interno) para establecer un Sistema de Gestión Ambiental (ISO, 2015):

-Contexto de la Organización (Requisito 4 NC 14001:2015)

-Liderazgo (Requisito 5 NC 14001:2015)

-Planificación (Requisito 6 NC 14001:2015)

-Apoyo (Requisito 7 NC 14001:2015)

-Operación (Requisito 8 NC 14001:2015)

-Evaluación del desempeño (Requisito 9 NC 14001:2015)

-Mejora (Requisito 10 NC 14001:2015) (ISO, 2015).

Las acciones ambientales en el destino se llevan a cabo a través de un movimiento nacional muy amplio llamado "Tarea Vida", en el que se identifican los principales problemas ambientales del país frente al cambio climático y se trazan los lineamientos para su materialización. A raíz de lo anterior y en concordancia con la NC ISO 14001:2015 se ha logrado incidir en algunas medidas de conservación ambiental. Entre los logros que más destacan se encuentran:

-El Sistema de Gestión Ambiental (SGA), con más del 60\% de sus instalaciones certificadas por las Normas ISO.

-Obtención de licencias ambientales en más del 70\% de las instalaciones en el destino, donde cada instalación implementa el Sistema de Gestión Ambiental con su Plan para 
el Manejo de los Desechos Sólidos y Desechos Peligrosos, la Política Ambiental, Plan de Ahorro y Reciclaje y el Plan de Manejo de Áreas Naturales Protegidas.

-Se plantea la participación del grupo en diferentes premios y certificaciones que garantizan la legitimidad de su gestión sostenible. Algunos de estos reconocimientos son: Reconocimiento Ambiental Nacional (RAN) que otorga el CITMA a 4 unidades anualmente; Certificación de los Sistemas de Gestión Ambiental de acuerdo con la Norma Cubana ISO 14001; Certificación de playas Bandera Azul (Gaviota, 2016); el Reconocimiento "Libre de CFC" que otorga la Oficina Técnica del Ozono del CITMA y Premio Internacional Puente de Alcántara 2001 al pedraplén Caibarién-Cayo Santa María (Mayoral, 2001).

-Instalación de tres plantas de tratamiento de residuos que minimizan los impactos de los desechos hacia el medio ambiente.

-Instalación de dos plantas desalinizadoras que reducen el consumo del agua potable en la región.

-Conservación de la biodiversidad de la región.

-Trabajo en conjunto con otras organizaciones para la protección de la flora y fauna autóctona. (MINTUR, 2016)

Además, en colaboración con el CITMA se lleva a cabo un Programa de Educación Ambiental para la comunidad de Caibarién, que funciona tanto dentro como fuera de las instalaciones, dirigido a los diferentes sectores claves de este territorio, y que cuyos resultados contribuyen al propósito de lograr, paso a paso, la implementación del Programa de Manejo Integrado de la Zona Costera del territorio. Existe en el territorio un Programa Ambiental que define la Meta 7.1.5., que consta de una serie de acciones encaminadas a contribuir a la sostenibilidad del turismo cubano, a partir de impactos positivos en la población local y el país. Dentro de las principales acciones que se llevan a cabo está la contribución, en la medida de lo posible, a las acciones de saneamiento ambiental de las comunidades cercanas, como la recogida de residuos sólidos, tratamiento a áreas verdes, limpieza, etc. (Gaviota, 2016).

Dentro de las actividades que se desarrollan dentro de las instalaciones están: la capacitación a los trabajadores, desarrollo de un programa de actividades educativas y de divulgación sobre la relación turismo-medio ambiente y la implementación de un Sistema de Gestión Ambiental. En la comunidad se promueve la creación de círculos de interés y sociedades científicas en todos los centros de educación relacionadas con la temática ambiental, se desarrollan eventos en saludo a las efemérides ambientales como festivales y concursos infantiles y actividades divulgativas sobre temas ambientales en los lugares de mayor afluencia de personas (Gaviota, 2016).

$\mathrm{Al}$ cliente se le brinda información por diversos medios (bienvenidas, actividades de animación, servicio de guías, durante las transportaciones, y en general los trabajadores de "primera línea), acerca de los valores de la biodiversidad (flora y fauna, formaciones vegetales, comunidades animales) existentes en el entorno. Además, se sitúan señales identificativas en las principales especies arbóreas y de jardines con sus nombres, vulgar y científico, para información al turista. Por otro lado, se implantan Códigos de Conducta para clientes con aquellas medidas para la protección del medio ambiente que deben observar en la instalación u oferta, de acuerdo con las peculiaridades de cada lugar (Gaviota, 2016).

A pesar de lo anterior, existen problemáticas que afectan el medio ambiente desatadas por la propia actividad turística. Las principales no conformidades del destino en cuanto a la actividad turística, determinadas en los programas ambientales, están relacionadas con: 
-El mantenimiento constante y sistemático de los equipos que generan contaminación atmosférica y de ruido.

- La necesidad de reducir el uso de los recursos.

- Incidir en una mayor reducción de desechos.

- Controlar la gestión de desechos para su reciclaje.

-Mayor control en el accionar de los trabajadores y clientes.

- Controlar el vertimiento de objetos sólidos y contaminantes a los desagües.

- Controlar la entrada a la región insular de especies de flora y fauna invasoras.

-Pérdida de áreas de playa.

-Pérdida de fauna autóctona.

-Necesidad de mantener el flujo de equipamiento para lograr un correcto índice de higiene en todas las instalaciones.

- Lograr un control riguroso a nivel micro en el cumplimiento de todos los procesos de la

Estrategia Ambiental (MINTUR, 2016).

Además, en un estudio del CITMA del año 2016 se corroboró que existen problemas en el constante ajuste de los planes de crecimiento y explotación con un cada vez mayor uso de suelo natural e impactos ambientales propios de la actividad constructiva y de explotación. Se incrementan notablemente las habitaciones de partida, se hace uso de zonas naturales de amortiguamiento, se incrementan los impactos derivados de los modos constructivos, se agudiza el efecto visual de construcciones pesadas, se generan tipologías arquitectónicas no integradas al entorno, aumenta la pérdida de la biodiversidad y de la calidad de los paisajes, hay un sobre consumo de agua y energía, y la estructuración del ordenamiento se ve constantemente bajo presión de múltiples instituciones y entidades decisoras que se contraponen a los propios criterios de partida. (González y Álvarez, 2016)

La situación en la comunidad de Caibarién, por su parte, es un poco más crítica debido a la no existencia de un sistema de drenaje, de manera que gran parte de las aguas residuales de la ciudad se vierten en el litoral, razón por la cual las aguas del malecón están contaminadas. Además, por la falta de conciencia ambiental, existen determinadas áreas de la localidad convertidas en micro vertederos.

\subsection{Dimensión social.}

La satisfacción del cliente se mide constantemente a todos los niveles empresariales y en todos los espacios de los turistas. La principal herramienta de medición son las Encuestas Corporativas. A través de ellas se realizan las evaluaciones de desempeño de los trabajadores y directivos. Además, se hace una revisión constante de la reputación online de todos los hoteles en los principales sitios de opinión internacionales (TripAdvisor, Monarca, Booking, Trivago, Redes Sociales, etc.,) (MINTUR, 2016).

Se promueve el desarrollo de los RR. HH a través de una constante capacitación en temas relacionados con el mejoramiento de las habilidades personales y profesionales en la empresa. Esto se realiza a través de las Escuelas de Hotelería y Turismo, universidades y capacitaciones internas de personas con capacidades profesionales y pedagógicas. Existe la incorporación priorizada de los pobladores del entorno como trabajadores en las diferentes estructuras, trabajando por su promoción a cargos directivos. Según la empresa Gaviota S.A más del 90\% de los trabajadores son de procedencia local, además, el 73\% de los directivos son de la misma procedencia (Gaviota, 2016). 
Además, se garantizan las buenas condiciones de trabajo en las instalaciones, un clima laboral positivo donde el trabajador es escuchado a través de una comunicación eficaz, trato digno y encuestas de satisfacción. Los trabajadores participan en la toma de decisiones, tienen posibilidades de promoción, existe un sistema de rotación interna de puestos de trabajo, las condiciones de seguridad y salud al trabajador son garantizadas mediante una política de salud y seguridad en el trabajo impuesta por el gobierno y de obligatorio cumplimiento en todas las empresas cubanas. A través de la Constitución de la República de Cuba (PCC, 2019) se establecen las bases para garantizar la no explotación y acoso comercial sexual o de cualquier otra forma, especialmente a niños, adolescentes, mujeres y minorías. Además, no existe diferencia de género, religión, preferencia sexual o raza y se ofrece igualdad de oportunidad de empleo para cualquier persona, además de no permitirse el trabajo infantil.

Sin embargo, a pesar de lo anterior existen determinados aspectos intrínsecos en la propia actividad turística que son motivos de insatisfacción y alto grado de precariedad laboral. Primeramente, se encuentran los tipos de contrato, donde predominan los contratos temporales, lo cual provoca precariedad e inseguridad del empleo y altas tasas de rotación. Por lo tanto, el colectivo hotelero del sector está formado por una plantilla joven que permanece pocos años trabajando debido a la alta carga de trabajo de algunos puestos y por supuesto a la baja remuneración que percibe en relación con las horas trabajadas, con la existencia de turnos de trabajo rotatorios.

Otro aspecto que se presenta en la región y es característica del turismo cubano, son las pocas expectativas de promoción en base al nivel académico que presentan la mayoría de los trabajadores, ya que los titulados realizan labores inferiores a su categoría profesional, y hasta en otro campo diferente a sus estudios, lo que origina un grado de insatisfacción personal por el trabajo. Sin embargo, el nivel escolar en algunos cargos para algunos puestos básicos es superior a las necesidades del cargo a desempeñar, por lo que los demás que tienen las características y la motivación para ingresar no lo logran. La dirección también es sobrevalorada en el turismo cubano debido a que existe poca motivación en los cuadros de dirección y poca diferencia salarial entre los dirigentes y los subordinados, lo que no estimula el deseo de promoción en los trabajadores. Por último, con la llegada del sector privado las ofertas laborales tienen mejores sistemas de estimulación por lo que ha causado un desplazamiento de la demanda hacia este sector. (MINTUR, 2016)

Dentro de las instalaciones se promueve la cultura regional y nacional en todas las actividades de animación que se desarrollan en las entidades hoteleras, así como las tradiciones culinarias y arquitectónicas que forman parte del producto turístico ofertado. También se define la protección de los valores históricos y socioculturales en los sitios donde se localizan las instalaciones y ofertas. Para lograr lo anterior, existe una plataforma de colaboración establecida entre el Ministerio de Cultura (MINCULT), la Unión Nacional de Artistas y Escritores (UNEAC), el Ministerio del Turismo (MINTUR), y el Grupo Gaviota S.A, la cual evalúa mensualmente la gestión de propuestas culturales en el destino. (MINTUR, 2016)

Sin embargo, como se produce un éxodo de profesionales hacia el turismo, hay un déficit laboral en los servicios culturales y el comercio, así como en la salud y en la educación, donde el personal sobrepasa los 40 años, o se suplen con estudiantes que una vez graduados aspiran a incorporarse también a la actividad turística. Por lo tanto, existen pocas opciones para los jóvenes y adolescentes, escasean los centros nocturnos y espacios para su esparcimiento, más aún en moneda nacional.

Las actividades de las instituciones culturales tienen un público ya establecido y mayoritariamente adulto, salvo las que se realizan directamente en centros escolares. También existen contrastes de la imagen paisajística urbana entre las áreas de residencia de la población 
empleada en el turismo y el resto de la ciudad. Y, a su vez, se presenta la asunción de modelos foráneos en las costumbres y hábitos de esta parte de la población, en el sentido de que ésta ha adoptado estilos, modos y conductas de vida ajenas a la localidad y al contexto del país.

Las estrategias de seguridad, protección y control del destino asumen la seguridad como factor determinante para el éxito. El país ha logrado un posicionamiento en el mercado turístico basado en el clima de paz, seguridad y protección al visitante, mediante niveles elevados de estabilidad político-social. Como consecuencia, el destino ofrece un nivel de garantía elevado permitiendo una visita tranquila, alejada de la violencia y el desorden público con los cuales se relacionan hechos delictivos que ponen en riesgo al visitante.

Uno de los problemas que trae el turismo, no obstante, es el concerniente a los accidentes de tráfico debido al elevado flujo peatonal-vehicular en las zonas de accesos y salidas de la ciudad (ONEI, 2019a) y a la propia idiosincrasia de muchos turistas a lo hora de conducir en el territorio. A pesar de que se realizan varias acciones para disminuir estos problemas que afectan a la población en general como el control peatonal y vehicular por autoridades locales, la mejora y ampliación de las vías y las señales de tránsito, el control vehicular por parte de las agencias transportistas, etc., estos aún persisten. En cuanto a la relación turista-anfitrión se dan casos de asedio a turistas, aunque en pequeña escala, por parte de personas de bajo nivel cultural, baja fuente de ingresos económicos, personas discapacitadas, con problemas mentales, que insisten en este tipo de comportamiento.

El Programa de Superación Integral para Jóvenes constituye una oportunidad de educación y preparación política e ideológica, donde a través de la Unión de Jóvenes Comunistas (UJC), organización política que está presente en todas las unidades turísticas a través de los llamados Comités de Base y que posee lazos estrechos con la oficina municipal, promueve determinados valores comunes y contribuye a la creación de nuevas oportunidades de acceso a la educación y elevar su nivel cultural y profesional. También está en funcionamiento la línea de adolescentes y jóvenes del Proyecto de Prevención de ITS-VIHSIDA, donde se aplica un programa en conjunto con la comunidad, con una estrategia que imposibilita el debilitamiento de las relaciones que unen al individuo con la sociedad a través de diferentes acciones dentro de las instalaciones hoteleras.

En conjunto con la constructora ALMEST, perteneciente al GAE, se han creado las condiciones necesarias para instalar a trabajadores en hogares construidos para uso exclusivo de los mismos y sus familiares. Estas viviendas tienen un alto grado de confort y calidad y existe la posibilidad de que se le atribuya como propiedad privada al trabajador luego de 10 años habitándola y siendo parte de la empresa. Dichos hogares están ubicados en zonas donde solo habitan personal de Gaviota S.A y donde se han creado las condiciones no solo para sus trabajadores sino también para suplir las necesidades de los familiares mediante la creación de escuelas, centros de abastecimiento, centros de recreación y áreas de uso público. Esto ha provocado el desplazamiento desde otros municipios hacia Caibarién y el consecuente aumento de la población residente en la comunidad.

Con el apoyo de la Federación de Mujeres Cubanas (FMC) se buscan soluciones a través de determinadas tareas encaminadas a prevenir la violencia familiar y la prostitución, entre muchas otras. No solo con la FMC se realiza esta labor, sino que también se lleva a cabo un trabajo en conjunto con otras organizaciones como la Comisión de Atención a Menores, debido a que los niños son un grupo vulnerable al turismo y su efecto en la mercantilización del pensamiento, por lo que se establecen programas referentes al uso indebido de la tecnología, se promueven valores éticos y se llevan a cabo programas de prevención de drogas y atención a la drogodependencia. También se imparten cursos de orientación y adiestramiento a la mujer y a su familia en las instalaciones hoteleras auspiciados por la FMC. 
Por otro lado, se evidencia el apoyo a proyectos sociales donde el grupo Gaviota S.A tiene una colaboración voluntaria con la sociedad mediante la participación en programas de donación de recursos a diversas organizaciones que promueven la ayuda humanitaria como son los Círculos Infantiles, escuelas primarias, las Casas Hogar de niños sin familia y las salas de hospitales infantiles especializadas en el control y tratamiento de enfermedades. También participa en proyectos y donaciones que benefician a las Casas de Abuelos, los centros psiquiátricos y los Centros de Asistencia Social a la población. En situaciones de desastres naturales o provocados por el hombre el apoyo organizacional se hace presente tanto en donaciones como en apoyos de rescate y recuperación.

Sin embargo, existen aspectos de la actividad turística que influyen negativamente en la vida social de la población en general. Primeramente, se producen procesos sociales como lo son los cambios en el comportamiento ideológico de las personas, producto de la diferenciación económica y social que les atribuye su posición con relación al turismo, percibiéndose un sentido de inferioridad de la población en general en comparación con las personas que trabajan directamente con el turista, ya que esta tiene mayores posibilidades de acceso a instalaciones turísticas debido a las diferencias económicas entre ellos. También se proyecta una mayor diferenciación social dentro de sus propias familias donde se presenta la falta de atención a los hijos y familiares debido al sistema de trabajo que se imponen.

\subsection{Dimensión Económica.}

Con la llegada del turismo a la región y el establecimiento de la industria como la principal fuente de ingresos de los residentes y de la región en general, se ha incrementado el empleo en un 55\% en los últimos años (ONEI, 2019a), donde en 2018 el 16\% de la población en general trabajaba en entidades turísticas hoteleras y extra hoteleras en el destino. Para un sector minoritario el turismo ha implicado una mejoría al tener la posibilidad de percibir ingresos en divisas por concepto de arrendamiento de sus viviendas; otro sector emergente de producción orientado hacia el turismo, en el que se incluyen artesanos y los trabajadores del sector que también perciben de forma directa los beneficios. Además, se manifiesta un mejoramiento en las fachadas de las viviendas y una reactivación de la economía local con el consecuente aumento del circulante y el incremento del poder adquisitivo de la población en general. (González y Álvarez, 2016)

La situación actual de la economía mundial afecta el desarrollo del destino por lo que su análisis es el primer eslabón de todos los planes de desarrollo en la región. Por otro lado, la política norteamericana hacia Cuba ha mantenido, desde octubre de 1960, un embargo o bloqueo económico, político y financiero que se encarga de "consolidar la confrontación y la hostilidad, tanto en el plano declarativo como en la ejecución de medidas de agresión económica contra el país" (DGAMDI, 2019, p. 5). Se puede afirmar que, desde abril de 2018 hasta marzo de 2019, el bloqueo ha causado pérdidas al país de aproximadamente de más de 4,5 mil millones de dólares solo en este período (DGAMDI, 2019). Si se contabiliza desde sus inicios, los daños acumulados durante casi seis décadas alcanzan la cifra de cerca de 139.000 millones de dólares y "si se toma en cuenta la depreciación del dólar frente al valor del oro en el mercado internacional, el bloqueo ha provocado perjuicios cuantificables por más de $922 \mathrm{mil}$ millones de dólares" (DGAMDI, 2019, p. 6). En su interior el bloqueo está basado en numerosas leyes que atentan contra la soberanía de Cuba y los derechos humanos. Con la imposición de las leyes y regulaciones internas la economía nacional, y principalmente el comercio y el turismo, arrastran incontables perdidas que imposibilitan el crecimiento constante y la generación de ingresos que satisfagan las necesidades de desarrollo económico del país. 
Cada año se registran las estadísticas nacionales en cuanto al turismo a nivel nacional y regional. Con la llegada a Cuba en el 2018 de 4.711.910 turistas con 19.179.751 pernoctaciones (ONEI, 2019b) se cumple el plan nacional de desarrollo que planteaba la llegada de 4.700.000. Sin embargo, ha mostrado una tasa de crecimiento de $1.3 \%$ con respecto al año anterior. En cuanto a las estadísticas en el polo turístico Cayos de Villa Clara se muestra que en el año 2018 arribó al destino el $11.6 \%$ de los turistas a nivel nacional.

Las principales acciones de comercialización en el destino son llevadas a cabo por las cadenas extranjeras que se establecen en el destino mediante contratos de administración y Join Venture. Estos contratos establecen que las cadenas hoteleras extranjeras obtienen un $49 \%$ de las utilidades de las instalaciones que manejen y entre sus obligaciones está garantizar la comercialización del hotel en el exterior, administrar la instalación mediante la implementación del know how de la marca, así como garantizar la operatividad de esta. Los mercados internacionales son movidos fundamentalmente por los turoperadores internacionales: Vacances Air Transat, Tours Mont Royal, Air Canadá Vacation, Hola Sun/Caribe Sol, Eurovips Argentina, Freeway, Havanatur Argentina, Julia tours, Ola Argentina, Soles Fun \& Leisure y Vacaciones Barceló Argentina entre otros. Además, el destino se comercializa a través de las distintas agencias de viajes del país.

En Cuba existe una doble circulación monetaria, de moneda nacional $(\mathrm{MN})$ y el peso convertible cubano (CUC). Si se toma en cuenta que los precios en instalaciones turísticas están fijados en CUC, se crea una situación contradictoria para la comercialización óptima del turismo nacional, que depende de una renta que pueda ser convertible en ambas monedas: $\mathrm{MN}$ y CUC. La moneda oficial es el MN, cuya importación o exportación está prohibida; mientras el CUC posee fuerza liberatoria dentro del territorio nacional y es equivalente al euro y otras divisas. La tasa de cambio es de $1 \mathrm{CUC}$ por 25 pesos $\mathrm{MN}$, por tanto, el turista nacional que recibe su renta en $\mathrm{MN}$ debe realizar la conversión para poder acceder al servicio turístico, cuyos precios están establecidos en CUC.

Por otra parte, sobre el dólar norteamericano existe un gravamen del $10 \%$ al cambio. Esto constituye un factor importante en la decisión de los turistas de viajar al país, por lo que varios medios de comunicación y agencias de viaje aconsejan a los visitantes de viajar con otras divisas que no sean el dólar americano. Para facilitar el servicio y evitar molestias a algunos turistas internacionales, existe la ventaja de poder efectuar los pagos directamente con Euros. Es posible cambiar cualquier moneda, incluso dólares americanos, a CUC en aeropuertos, bancos, hoteles y volver a canjearlos al término de la estancia en el país. Se aceptan tarjetas de crédito Cabal, Transcard, Visa y MasterCard siempre que no hayan sido emitidas por bancos estadounidenses o sus filiales. Existen, además, medios de pago de uso nacional emitidos por el Banco Financiero Internacional (tarjetas BFI) y por los bancos de Crédito y Comercio, Metropolitano, Popular de Ahorro (BPA) y BICSA (tarjetas Red).

Cuba garantiza la estabilidad política y monetaria; además, existe una voluntad política gubernamental de promover el turismo. Como establece la Constitución en el artículo 18: "En Cuba rige un sistema de economía socialista basado en la propiedad de todo el pueblo sobre los medios fundamentales de producción como la forma de propiedad principal..." (PCC, 2019, p. 3). El estado cubano es dueño o participa mediante empresas mixtas con capitales extranjeros en el desarrollo del destino. Los ingresos provenientes del turismo se revierten en el desarrollo integral del país; es necesario destacar además que el Ministerio del Turismo colabora en el desarrollo de la actividad turística. Cuba no se sustrae de la globalización mundial, pero es oportuno señalar que no se encuentra influenciada por las políticas económicas del Fondo Monetario Internacional (FMI) y el Banco Mundial (BM). 
La economía territorial es incentivada mediante la diversificación de otros servicios al turismo, como las esferas de producción, como agropecuaria, industrial, y materiales constructivos. Esto trae consigo una activación de la producción debido a las nuevas demandas de productos como frutas, vegetales, hortalizas, etc., que hoy se producen en baja escala. De igual forma incide en la economía regional al demandar productos del mar y cárnicos, fortaleciendo los mecanismos establecidos para incentivar las relaciones productivas y la cadena de valor entre las empresas del territorio. Con las nuevas actualizaciones de la política económica interna del país, la producción regional se ha beneficiado del turismo desarrollado en la región, así como las instalaciones hoteleras han encontrado los proveedores necesarios para las necesidades urgentes de la actividad. Gracias al surgimiento de pequeñas y medianas empresas privadas productoras y prestadoras de servicios, la solución de los problemas es hoy más rápida de lo que era en años anteriores.

Con el aumento de los contratos de PyMEs privadas locales aumenta el ingreso directo por turismo en las localidades adyacentes y el consecuente aumento del activo circulante. Además, se fomenta la creación de nuevos empleos diversificados en la región permitiendo que los ingresos por turismo se retengan en la localidad. Por su parte, los empleados perciben un mayor ingreso salarial por las propinas que reciben de los clientes en su labor diaria, además de la repartición de utilidades de las instalaciones.

Por otro lado, los ingresos que se generan por turismo se dirigen directamente al Estado, el cual es el encargado de distribuirlo de acuerdo con las necesidades del país. Detallando lo anterior, se puede constatar que una parte de los ingresos regresa a la misma actividad turística para los procesos de inversión y planes de mejora, otra parte se dirige a las entidades estatales presupuestadas como son salud, educación y canasta básica (alimentos básicos distribuidos por núcleo familiar a precio menor al costo). Es importante destacar que el orden de los planteamientos señalados no es estandarizado, por lo que a decisión del Estado se destinan los recursos a las necesidades imperantes del momento histórico. A pesar de que no exista un beneficio económico directo para la población local, existen por parte de las instalaciones hoteleras donaciones en especie a diferentes instituciones sociales que promueven el desarrollo y el bienestar social, tal es el caso de entidades de salud, educación y ONGs.

Sin embargo, a pesar del crecimiento acelerado que ha tenido la industria turística en el país los ingresos no son suficientes para garantizar una alta calidad de vida a toda la población en general, ni logra llegar a todos los sectores para la satisfacción de sus necesidades básicas. Junto a esto se enuncia el embargo económico impuesto por los EE. UU hacia Cuba que imposibilita el crecimiento sostenido de la economía nacional y por consecuente la mejora de la satisfacción económica de la población.

Por otro lado, se ven reflejados impactos negativos que contrarrestan beneficios para la comunidad en general. Estos aspectos se basan en la existencia de un aumento significativo en los volúmenes de demanda de agua, electricidad y comunicaciones para la insuficiente oferta, lo que ha traído el aumento significativo en el precio de los productos principalmente los alimenticios de necesidades básicas y la sobre valoración monetaria; por último, se presenta una mayor circulación del Peso Convertible (CUC) sobre la Moneda Nacional (MN). Esto ocurre porque la principal moneda de ingresos de los trabajadores del turismo en CUC, sin embargo, el resto de los residentes obtienen sus ingresos en MN. Por lo tanto, se evidencia la diferenciación económica entre los trabajadores del turismo con el resto de la localidad.

\section{Discusión de resultados}


Es importante destacar que el desarrollo sostenible es un proceso de incremento sostenido y equitativo de la calidad de vida de la población, mediante el cual se asegura el crecimiento económico y la prosperidad social, en una relación armónica con la protección del medio ambiente, de modo que se satisfacen las necesidades de las actuales generaciones, sin poner en peligro las de las generaciones futuras (CITMA, 2014). En función de lo anterior, se puede constatar que en la isla se tiene en cuenta el establecimiento de la industria turística conforme a las políticas nacionales y provinciales de desarrollo integrado, en armonía con las áreas de la economía y la sociedad que incluyen las políticas sociales y sus prioridades reconocidas en todos los niveles. Unido a lo anterior, el desarrollo del polo turístico Cayos de Villa Clara está planificado como un área de actividades específicas para el turismo separada de las áreas residenciales. Esto permite que los impactos negativos del turismo en la comunidad no sean tan perjudiciales para la calidad de las áreas de residencia. La descripción de los indicadores sostenibles identificados permite hacer reflexiones respecto al nivel de sostenibilidad en la relación del turismo con la comunidad e identificar algunas de las posibles variables que pueden estar incidiendo en ella.

\subsection{Sostenibilidad Ambiental}

El cuidado ambiental en Cuba forma parte de las acciones del Gobierno desde el inicio de la Revolución Cubana, donde se llevaron a cabo operaciones que cambiaron el curso de la conservación de la biodiversidad en el país y el desarrollo sostenible del ambiente natural (Vilamajó, Vales, Capote, Salabarría \& Menéndez, 2002). La política gubernamental ha imposibilitado el establecimiento de una sociedad consumista y una generación de desechos alarmante, mientras que la Educación Ambiental forma parte de la enseñanza de las personas desde edades tempranas y ha constituido un elemento clave en el establecimiento de una "política verde" en la isla.

Con la llegada del turismo, las actividades de ordenamiento territorial se basaron en explotar las áreas con potencialidades para el turismo de sol y playa siempre y cuando se conserve la biodiversidad y la capacidad de carga de las zonas seleccionadas. Con la creación de las Áreas Protegidas se estableció un poder legislativo y la creación de instituciones fuertes en el ámbito ambiental que fortalecen y amparan la conservación y protección del medio ambiente. Sin embargo, el turismo como actividad, a pesar de estar muy vigilado en el aspecto ambiental, ha traido consigo impactos negativos a las zonas en donde se desarrolla que son muy difíciles de eliminar. Tal es el caso de Cayos de Villa Clara, en donde la generación de desechos, la contaminación y la pérdida de la biodiversidad es aún un problema que afecta no solo a las zonas donde se desarrolla la actividad sino también a las poblaciones cercanas.

Por ello, las acciones de las empresas para incidir en la sostenibilidad ambiental en la comunidad de Caibarién están relacionadas principalmente con las actividades de saneamiento y educación ambiental (MINTUR, 2016). Sin embargo, con el crecimiento acelerado que está sufriendo el destino turístico Cayos de Villa Clara es importante incrementar el control ambiental y la ejecución de las políticas ambientales en todo el territorio con el fin de que los impactos negativos no vayan aumentando paralelamente. Por lo que se puede concluir, la estrategia de desarrollo de turismo de Gaviota S.A puede influir moderadamente en la sostenibilidad ambiental de Caibarién, debido a que disminuye los impactos del turismo y el cambio climático, pero condiciona también impactos negativos propios de la actividad turística que constituyen problemáticas para los residentes.

\subsection{Sostenibilidad social.}

Cuba es un país con características políticas que le diferencian de otros en el mundo, donde la política social está fundamentada en las bases de un Sistema Socialista (PCC, 2019), con características que han nacido de los 60 años de restructuraciones en su Constitución 
(DGAMDI, 2019) para adaptarse a los cambios del sistema mundial y la globalización neoliberal. Las empresas cubanas, y en especial las estatales, se rigen estrictamente por las políticas del Estado y tienen la obligación de participar en las políticas de cohesión social de la población (PCC, 2019).

El turismo en Cuba es una actividad en proceso de crecimiento que se va incorporando paulatinamente a la sociedad y a las economías locales, regida por las bases de las políticas sociales del país. En este sentido, la industria debe integrarse compatiblemente, tanto al entorno económico y natural como al entorno social, cultural y humano contribuyendo así al desarrollo sostenible (PCC, 2019). Por lo tanto, el modelo de desarrollo turístico incluye en sus políticas turísticas los impactos sobre el patrimonio cultural y los elementos sociales tradicionales de la comunidad residente donde el sustento a su identidad e intereses forma parte de la cultura organizacional de todas las entidades turísticas.

Las empresas turísticas se comprometen estrictamente a promover los valores socialistas y procurar la estabilidad social en sus trabajadores y en la comunidad local (MINTUR, 2016). Las principales acciones se encabezan en garantizar el bienestar social de sus trabajadores e incidir en la mitigación de los problemas sociales de las comunidades adyacentes a través de iniciativas propias y de colaboraciones con ONGs y organizaciones políticas de masas (PCC, UJC, FMC, etc.) encargadas de llevar a cabo las acciones de cohesión social en todo el país. Dichas acciones constituyen una cotidianeidad en la vida laboral y social de todos los residentes. Además, todas estas acciones han contribuido a disminuir los efectos sociales negativos del turismo en la sociedad cubana. La no discriminación, la igualdad de derechos, la justicia social y la conservación de la historia y la cultura contribuyen a frenar los impactos de la actividad turística derivados de sus bases capitalistas, al menos desde el curso teórico, político e institucional.

Sin embargo, el desarrollo tecnológico y la apertura de Cuba al Internet, los cambios en las políticas del gobierno de EE. UU contra Cuba y el cambio en las políticas económicas y migratorias en la isla han sumergido a la sociedad cubana en el proceso de transculturación que acarrea la globalización neoliberal (DGAMDI, 2019). Debido a esto, se han manifestado en la población cubana cambios en las costumbres cotidianas y en la forma de vivir con injerencia capitalista, lo que ha significado un choque constante entre ideales dentro de un mismo contexto, donde la población adquiere nuevas necesidades que no están en concordancia con el entorno político y social en el que se desarrollan. El turismo constituye un factor influyente más en estos cambios debido a que la constante interacción entre trabajadores y turistas incentiva la transculturación, con lo que se afecta la vida de los residentes.

Por otro lado, debido al carácter estatal de las empresas, muchos de los procesos sociales que se desarrollan en la comunidad quedan deslindados de la acción directa de la mismas, o bien no son reconocidos por toda la comunidad al no utilizarse el apoyo social como herramienta de promoción turística, sino como política social en manos del Gobierno enlazada a la vida social de todos los residentes en todas las etapas de su vida, constituyendo un elemento de cotidianidad y poca relevancia para la percepción del turismo en la vida social de los residentes.

Evaluando la incidencia del turismo en la sostenibilidad social de la comunidad de Caibarién se puede concluir que si puede existir un cierto grado de influencia dependiendo de la percepción de cada individuo de la comunidad y su papel en los procesos sociales en los que esté involucrado. Las principales influencias positivas se manifiestan de forma indirecta y a través de las políticas públicas del Gobierno en los diferentes niveles de dirección. Es importante destacar que también existe una influencia negativa manifestada en la creación 
inconsciente de diferencias sociales entre trabajadores y el resto de los residentes que, a pesar de ser disminuida por las demás acciones sociales, se reconoce aún su establecimiento.

\subsection{Sostenibilidad Económica.}

El desarrollo del turismo ha sido de alta prioridad económica para Cuba, como vía para enfrentar la crisis económica (Rueda, 2003). Las empresas turísticas que pertenecen al sector estatal de la economía dirigen sus ingresos en un $100 \%$ al Estado, en tanto que las empresas extranjeras, mediante contratos de administración, retienen el $51 \%$ de los ingresos en el territorio nacional. Esto significa que la empresa en sí no distribuye los ingresos de manera autónoma, por lo que la población de Caibarién puede no percibir de manera directa, en escala local, los beneficios económicos.

Sin embargo, indirectamente se da un aumento del nivel de vida en la comunidad debido al gran número de empleos que se han creado, en donde los empleados perciben beneficios económicos provenientes de la actividad, dentro de lo que se manifiestan la existencia del beneficio adicional de la propina en CUC en las instalaciones hoteleras, la creación de poblados para empleados con servicios complementarios, la estimulación de la economía local y el activo circulante, entre otros. A raíz de esto, se establen en Caibarién incentivos para la desintegración social, dado que se presentan características económicas diferentes en el poder de adquisición y nivel de vida de los trabajadores y sus familiares directos respecto a los del resto de los residentes.

Por otro lado, en el país existe una crisis económica causada por el bloqueo económico implantado por EE. UU sobre la isla y que ha desestabilizado la economía a nivel nacional (DGAMDI, 2019), así como por problemas estructurales más directamente relacionados con la obsolescencia del sistema económico socialista. No obstante, se puede constatar que las políticas del Estado, en función de garantizar la distribución de la riqueza y lograr mantener los servicios subsidiados a la población, han incidido, con resultados desiguales, en algunas acciones para disminuir la diferenciación entre los pobladores y en la desigualdad económica. En este aspecto, se han desarrollado cambios positivos en la política económica del país (PCC, 2019), que han permitido un mayor nivel de participación de los residentes en la actividad turística y por ende han comenzado a percibir beneficios directos del turismo en la población residente a través de alianzas entre pymes y las empresas turísticas.

Por lo tanto, la incidencia del turismo en la sostenibilidad económica en Caibarién se desenvuelve en un conflicto entre el enfrentamiento al embargo económico, la satisfacción de las necesidades constantemente crecientes de la población al adoptar modelos neoliberales de consumo arraigados de la propia actividad turística y a garantizar la distribución equitativa y justa de los beneficios. Entonces se puede argumentar que de manera indirecta el turismo si puede favorecer la sostenibilidad económica de la comunidad de Caibarién.

Como se puede constatar el turismo tiene un grado moderado de incidencia en la sostenibilidad de la comunidad de Caibarién debido a las acciones indirectas que realiza basadas en las políticas y valores de la Constitución de Cuba. Dichas acciones son consideradas por los residentes como parte de la cotidianidad de la relación entre el gobierno, las organizaciones políticas de masas y las empresas estatales con la población. Además, los cambios producidos en la comunidad tanto por el gobierno, como por el resto de los actores sociales, han incidido en el aumento de la sostenibilidad percibida de los residentes. Dicho estudio valida las investigaciones previas de González (2011) y Herrera \& Montero (2009).

\section{Conclusiones}

Esta investigación ha indigado acerca de la influencia del turismo en la sostenibilidad de la comunidad objeto de estudio. Esto no significa que los resultados no se puedan generalizar 
para otros territorios, debido a que la industria turística en Cuba es manejada en su totalidad por el Estado Cubano y todas las empresas tienen las mismas bases estratégicas, por lo que los resultados pueden ser similares para cualquier territorio con características geográficas y demográficas similares, en el mismo ámbito del país.

Este estudio se centró en análisis de las empresas locales mediante el análisis de información documental y proveniente de entrevistas semiestructuradas dirigidas a informantes seleccionados; este estudio utilizó a Caibarién como muestra para evaluar la incidencia del turismo en la sostenibilidad de la comunidad. Por lo tanto, los resultados de la descripción de los indicadores sostenibles señalados revelan la adopción de diversas estrategias de gestión que contribuyen a mejorar las percepciones de los residentes y fomentar el desarrollo de un turismo sostenible en la región. Por lo anterior, este estudio llena un vacío en las investigaciones referentes a la incidencia del turismo en la sostenibilidad y contribuye a la literatura especializada con un alto valor en el ámbito nacional cubano y como ejemplo empírico internacional.

Por otro lado, el estudio proporcina un análisis del turismo en la región y su influencia en la sostenibilidad de los residentes de Caibarién, donde los resultados indicaron que el turismo influye indirectamente en la sostenibilidad de la comunidad de Caibarién bajo los preceptos del contexto político y social en el que se desarrollan ambas partes.

Se encontró evidencia de que la dimensión ambiental del turismo en la región tiene un marco regulatorio fuerte, que ampara la protección al medio ambiente en los procesos de gestión, lo que ha garantizado la mitigación del impacto negativos del turismo al ambiente. Sin embargo, aún con ello, se presentan en la región analizada algunos problemas que afectan a la sostenibilidad ambiental. Por su parte, la dimensión social está basada en las bases del Sistema Político y Social Cubano, por lo que las acciones sociales y el impacto positivo en las comunidades es un aspecto explícito en la gestión turística de la empresa. Esto ha permitido mitigar el impacto negativo de la actividad turística en los residentes, pero aún existen problemas que afectan la sostenibilidad social de la empresa. En el caso de la dimensión económica, ésta constituye un reto para la gestión turística en Cuba debido a que se enfrenta a factores internos y externos que impiden el desarrollo económico progresivo y eficiente. Sin embargo, los beneficios económicos son tangibles en la comunidad de Caibarién.

Una limitación en el presente trabajo es que no se analizó la percepción general de la población, mediante alguna herramienta cuantitativa, por lo que sus actitudes psicológicas o emocionales hacia el desarrollo del turismo no se reflejan apropiadamente (Hunt y Stronza, 2014). Para superar esta condición, las investigaciones futuras deberían concentrarse en evaluar el impacto del turismo en la vida de los residentes utilizando tanto enfoques cuantitativos como cualitativos para comprender mejor el impacto del turismo en la región analizada. Asimismo, sería deseable realizar comparativos con otros sitios turísticos dentro y fuera de Cuba, así como seguimientos con enfoque longitudinal, con el objeto de observar la posible transición del impacto del turismo y su percepción a lo largo del tiempo, en la misma medida en la que se desarrolla el turismo a lo largo de su ciclo de vida (Butler, 1980).

El desarrollo sostenible es una aspiración que ha sido planteada como paradigma ante la globalización neoliberal, por lo que parecería ser también un modelo elaborado exprofeso para aplicarse en el ámbito del capitalismo. Sin embargo, cuando se concibe a la sostenibilidad de manera más amplia, no restringida a cierto tipo de sistema político o económico, se constituye a su vez como una orientación hacia la cual han de dirigirse los esfuerzos hacia el desarrollo, en la búsqueda del equilibrio en sus dimensiones social, económica y ambiental.

\section{Anexo. Guía utilizada para las entrevistas (agosto de 2019)}




\begin{tabular}{|c|c|c|}
\hline ÁREA & ENFOQUE & PREGUNTAS \\
\hline $\begin{array}{l}\text { Recursos } \\
\text { Humanos }\end{array}$ & $\begin{array}{l}\text { Dimensión social } \\
\text {-Gestión RR HH } \\
\text {-Programas } \\
\text { sociales } \\
\text {-Indicadores }\end{array}$ & $\begin{array}{l}\text { 1. ¿La organización cumple con toda la legislación y los reglamentos } \\
\text { pertinentes, nacionales e internacionales? } \\
\text { 2. ¿Qué procedimientos se utilizan para la gestión sociocultural en el } \\
\text { destino? } \\
\text { 3. ¿Cómo es el proceso de selección y contratación de personal? } \\
\text { 4. ¿Cómo se lleva a cabo el proceso de motivación del personal? } \\
\text { 5. ¿Son considerados los residentes de la comunidad para cargos } \\
\text { directivos? } \\
\text { 6. El personal recibe capacitación periódica relacionada a las prácticas } \\
\text { ambientales, sociales, culturales, ¿de salud y de seguridad? } \\
\text { 7. ¿Cómo se evalúa la satisfacción del personal? ¿Están identificadas las } \\
\text { principales problemáticas? ¿Se les da respuesta a sus inquietudes? } \\
\text { 8. ¿Cuáles son los beneficios que le otorga la empresa a los trabajadores } \\
\text { en su vida social? } \\
\text { 9. ¿Cuáles son las acciones encaminadas a conservar y promover la } \\
\text { historia, cultura y tradiciones locales dentro de las instalaciones } \\
\text { hoteleras y como se vinculan a la gestión de las cadenas hoteleras? } \\
\text { 10. ¿Están identificados los principales problemas sociales de la comunidad } \\
\text { de Caibarién? } \\
\text { 11. ¿Cuáles son las iniciativas en pro del desarrollo comunitario social } \\
\text { (educación, capacitación, salud y saneamiento)? } \\
\text { 12. ¿Cuáles son las actividades que se desarrollan en la entidad para } \\
\text { disminuir los problemas sociales en la comunidad? } \\
\text { 13. ¿Cuáles considera usted que sean los principales impactos sociales } \\
\text { positivos y negativos del turismo que lleva a cabo la empresa en el } \\
\text { territorio? } \\
\text { 14. ¿Cómo se gestiona la seguridad de las instalaciones y de los clientes? } \\
\text { 15. ¿Cómo se lleva a cabo el proceso de transportación de trabajadores y } \\
\text { clientes y como se garantiza la seguridad de estos y de la población en } \\
\text { general? }\end{array}$ \\
\hline $\begin{array}{l}\text { Calidad y } \\
\text { Medio } \\
\text { Ambiente }\end{array}$ & $\begin{array}{l}\text { Dimensión } \\
\text { ambiental } \\
\text {-Gestión } \\
\text { Ambiental } \\
\text { del destino } \\
\text {-Incidencia en la } \\
\text { localidad. }\end{array}$ & $\begin{array}{l}\text { 1. ¿Cuáles son los objetivos estratégicos en el ámbito ambiental? } \\
\text { 2. ¿Poseen Política Ambiental? } \\
\text { 3. ¿En qué marco legal está respaldada la estrategia ambiental? } \\
\text { 4. ¿Con cuales organizaciones colabora para la gestión ambiental del } \\
\text { territorio? } \\
\text { 5. ¿Qué procedimientos se utilizan para la gestión ambiental? } \\
\text { 6. ¿Cuáles son las medidas para el control de las construcciones de la } \\
\text { infraestructura? } \\
\text { 7. ¿Están declarados los principales problemas ambientales de la región? } \\
\text { 8. ¿Cuáles son los principales impactos ambientales positivos y negativos } \\
\text { 9e la actividad turística de la empresa? } \\
\text { 10. ¿Qué medidas se llevan a cabo para mitigar los impactos negativos? } \\
\text { 11. ¿Cómo se controla la generación de desechos? } \\
\text { 12. ¿Existen programas de ahorro de recursos? } \\
\text { 13. ¿Cuentan con programas de Educación Ambiental? } \\
\text { 14. ¿Cuáles son las iniciativas de la empresa en función de proteger y } \\
\text { conservar el medio ambiente no solo en la zona de explotación sino } \\
\text { también en las zonas aledañas? } \\
\text { 15. ¿Como se mide la satisfacción de los clientes? } \\
\text { 16. ¿Cuáles son las ventajas y desventajas que tiene el turismo cubano sobre } \\
\text { turismo a nivel internacional? }\end{array}$ \\
\hline
\end{tabular}




\begin{tabular}{|c|c|c|}
\hline Economía & $\begin{array}{l}\text { Dimensión } \\
\text { económica } \\
\text {-Gestión } \\
\text { Económica } \\
\text {-Beneficios } \\
\text { económicos para } \\
\text { RR HH } \\
\text { localidad. }\end{array}$ & $\begin{array}{l}\text { 1. ¿Cuál es la situación con los proveedores locales? ¿Existen } \\
\text { colaboraciones con los mismos? ¿Qué ventajas tiene para la empresa } \\
\text { estos contratos? } \\
\text { 2. ¿Como se establecen los contratos de administración con las compañías } \\
\text { extranjeras? } \\
\text { 3. ¿Existen apoyos económicos o beneficios que se destinan al beneficio } \\
\text { de la comunidad de Caibarién? } \\
\text { 4. ¿Cómo afecta la dualidad monetaria que existe en el país a la empresa? } \\
\text { 5. ¿Cuáles son los factores nacionales e internacionales que afectan la } \\
\text { economía de la empresa? } \\
\text { 6. ¿En que ha afectado el embargo económico impuesto por EE. UU a la } \\
\text { empresa? } \\
\text { 7. ¿Cómo se lleva a cabo el proceso de comercialización del destino? } \\
\text { 8. ¿Cómo se ha comportado el crecimiento habitacional y de servicios } \\
\text { desde que comenzó el turismo en el destino? } \\
\text { 9. ¿Cuáles son las ventajas y desventajas en materia económica que tiene } \\
\text { el turismo cubano sobre turismo a nivel internacional? } \\
\text { 10. ¿Cuáles considera usted que sean los principales impactos económicos } \\
\text { positivos y negativos del turismo que lleva a cabo la empresa en el } \\
\text { territorio? }\end{array}$ \\
\hline
\end{tabular}

Fuente: Elaboración propia.

\section{Referencias}

Alam, M. S., \& Paramati, S. R. (2016). The impact of tourism on income inequality in developing economies: ¿Does kuznets curve hypothesis exist? Annals of Tourism Research, 61, 111-126.

Andereck, K. L., Valentine, K. M., Knopf, R. C. y Vogt, C. A. (2005). Residents' perceptions of community tourism impacts. Annals of Tourism Research, 32, 1056-1076. doi: 10.1016/j.annals.2005.03.001.

Andriotis, K., \& Vaughan, R. D. (2003). Urban residents' attitudes toward tourism development: The case of Crete. Journal of Travel Research, 42, 172-185. doi:10.1177/0047287503257488.

Ap, J. (1992). Residents' perceptions on tourism impacts. Annals of Tourism Research, 19(4), 665-690.

Aquino, R. S., Lück, M., y Schänzel, H. A. (2018). A conceptual framework of tourism social entrepreneurship for sustainable community development. Journal of Hospitality and Tourism Management, 37, 23-32.

Asociación de Monitores Medioambientales Almijara (2008) "Turismo Sostenible. Definición del Turismo Sostenible”. Recuperado el 18 de febrero del 2019 en: http://www.turismosostenible.org/docs.php?did=

Bowers, J. (2016). Developing sustainable tourism through ecomuseology: A case study in the rupununi region of Guyana. Journal of Sustainable Tourism, 24(5), 758-782.

Cardoso, C. (2014) "Sosteniendo al Turismo o Turismo Sostenible". Estudios y Perspectivas en Turismo 23(2), 376-395.

CITMA (2014). Plan del Sistema Nacional de Áreas Protegidas 2014-2020. Recuperado el 20 de febrero de octubre de 2019 de: http://repositorio.geotech.cu/jspui/bitstream/1234/2454/1/Plan\%20de\%20sistema\%2020 14-2020.pdf.

Colglazier, M. (2015). Sustainable development agenda: 2030. Science, 349 (6252), 1048-1050. DOI: $10.1126 /$ science.aad2333. 
Davidson, L., \& Sahli, M. (2015). Foreign direct investment in tourism, poverty alleviation, and sustainable development: A review of the gambian hotel sector. Journal of Sustainable Tourism, 23(2), 167-187.

Dirección General de Asuntos Multilaterales y Derecho Internacional (DGAMDI) (julio, 2019). Informe de Cuba sobre la Resolución 73/8 de la Asamblea General de las Naciones Unidas. "Necesidad de poner fin al Bloqueo Económico, Comercial y Financiero Impuesto por los Estados Unidos de América contra Cuba". Ediciones MINREX. Recuperado el 25 de septiembre de 2019 en: http://www.minrex.gob.cu/sites/default/files/2019-09/Cuba\%20vs\%20Bloqueo.pdf.

Ecured (2018). Grupo Empresarial Gaviota S.A. Recuperado el 12 de febrero de 2019 de: https://www.ecured.cu/Grupo_de_Turismo_Gaviota_S.A.

Fyall, A., \& Garrod, B. (1998). Heritage tourism: At what price? Managing Leisure, 3(4), 213228.

Gaviota (2016). Programa Ambiental. Plan de Acciones. Caibarién, Cuba, documento no publicado.

Gaviota (2019). Sitio Web Oficial Gaviota S.A. Recuperado el 12 de febrero de 2019 de: https://www.gaviota-grupo.com.

González H. (2011). "Impactos percibidos del modelo turístico urbano en Remedios y Caibarién, Cuba. Retos para la sostenibilidad”. Revista de Análisis Turístico, 11, 23-34. ISSN: $1885-2564$.

González H, M. (2015). Perspectiva estratégica de la producción del espacio turístico en Remedios y Caibarién, Cuba. Producto de investigación. Recuperado el 12 de febrero de $2019 \mathrm{de}$ http://erecursos.uacj.mx/handle/20.500.11961/2715

González D. M. C., y Álvarez L. A. E. (2016). Ordenamiento y desarrollo del turismo en Cayo Santa María en Villa Clara. Arquitectura y Urbanismo, 37(1), 78-84. ISSN 1815-5898.

Hatipoglu, B., Alvarez, M. D., \& Ertuna, B. (2016). Barriers to stakeholder involvement in the planning of sustainable tourism: The case of the thrace region in Turkey. Journal of Cleaner Production, 111(16), 306-317.

Herrera, M. G., \& Montero, G. I. (2009). Impactos del turismo sobre los procesos de cohesión social Caibarién, Cuba. Estudios y perspectivas en turismo, 18(1), 53-68.

Hunt, C., \& Stronza, A. (2014). Stage-based tourism models and resident attitudes towards tourism in an emerging destination in the developing world. Journal of Sustainable Tourism, 22(2), 279-298.

ISO (2015). ISO 14001:2015(es) Sistemas de gestión ambiental - Requisitos con orientación para su uso. Recuperado el 9 de julio de 2019 en: https://www.iso.org/obp/ui\#iso:std:iso:14001:ed-3:v1:es

Laeis, G. C. M., y Lemke, S. (2016). Social entrepreneurship in tourism: Applying sustainable livelihoods approaches. International Journal of Contemporary Hospitality Management, 28(6), 1076-1093. https://doi.org/10.1108/IJCHM-05-2014-0235.

Lankford, S. V. y Howard, D. R. (1994). Developing a tourism impact attitude scale. Annals of Tourism Research, 21, 121-139. doi:10.1016/0160-7383(94)90008-6.

Lee, C. K., \& Back, K. J. (2006). Examining structural relationships among perceived impact, benefit, and support for casino development based on 4-year longitudinal data. Tourism Management, 27, 466-480.

Lee, T. H., Jan, F. H., \& Yang, C. C. (2013). Conceptualizing and measuring environmentally responsible behaviors from the perspective of community-based tourists. Tourism Management, 36, 454-468.

Lee, T. H., Jan, F. H., Tseng, C. H., \& Lin, Y. F. (2018). Segmentation by recreation experience in island-based tourism: A case study of taiwan's liuqiu island. Journal of Sustainable Tourism, 26(3), 362-378. 
Lee, T. H., \& Jan, F. H. (2019). Can community-based tourism contribute to sustainable development? Evidence from residents' perceptions of the sustainability. Tourism Management, 70, 368-380.

Liu, J. C. y Var, T. (1986). Resident attitudes toward tourism impacts in Hawaii. Annals of Tourism Research, 13, 193-214. doi:10.1016/0160-7383(86)90037-X.

Mayoral M. J. (2001). Recibe Fidel premio ganado por el pedraplén de Caibarién-Cayo Santa María. Granma. Recuperado el 10 de julio de 2019 de http://www.granma.cu/granmad/2001/11/07/nacional/articulo17.html

Melgar, M. (2004) "Ecoturismo como una alternativa de desarrollo local en el ejido Revolución". Universidad Autónoma de baja California, Tijuana.

MINTUR (2016). Estrategia Ambiental Nacional MINTUR, para los años del 2016 al 2020. Cuba, documento no publicado.

MINTUR, (2018). Plan de inversiones de Gaviota S.A. Santa Clara. Documento no publicado.

Nunkoo, R., \& Ramkissoon, H. (2010). Community perceptions of tourism in small island states: A conceptual framework. Journal of Policy Research in Tourism, Leisure and Events, 2, 51-65. doi:10.1080/19407960903542318.

Oficina Nacional de Estadística e Información ONEI (2015). “Estudios y datos de la población cubana. 2015". Recuperado el 12 de julio de 2019 de: http://www.one.cu/publicaciones/cepde/estudiosydatos/estudios_2015.pdf

Oficina Nacional de Estadística e Información (ONEI) (2019a). Anuario Estadístico de Caibarién 2018, Edición 2019. Cuba.

Oficina Nacional de Estadística e Información (ONEI) (2019b). Turismo Internacional. Indicadores Seleccionados. Enero - diciembre de 2018.

Organización Mundial del Turismo (OMT). (1997) "Desarrollo Turístico Sostenible. Guía para planificadores locales". Madrid.

Organización Mundial del Turismo (OMT). (2000) "Desarrollo Sostenible del Turismo: una compilación de buenas prácticas". Madrid

ONU (2018). "Informe de los objetivos de desarrollo sostenible 2018”. New York.

Partido Comunista de Cuba (PCC). (2017). Lineamientos de la Política Económica y Social del Partido y la Revolución para el período 2016-2021. Recuperado el 2 de febrero de: https://www.cubadebate.cu

Partido Comunista de Cuba (PCC). (2019). Constitución de la República de Cuba. Recuperado el 9 de julio de 2019 en: http://www.granma.cu/reforma-constitucional/2019-06-27/enpdf-nueva-constitucion-de-la-republica-de-cuba

Perdue, R. R., Tyrrell, T., \& Uysal, M. (2010). Understanding the value of tourism: conceptual divergence. In D. Pearce, \& R. Butler (Eds.), Tourism research: A 2020 vision. Oxford: Goodfellow Publishers, p. 123-134.

Peredo, B., y Wurzelmann, S. (2015). Indigenous tourism and social entrepreneurship in the Bolivian Amazon: Lessons from San Miguel del Bala. International Indigenous Policy Journal, 6(4). https://doi.org/10.18584/iipj.2015.6.4.5

Pérez de las Heras, M. (2004) "Manual de Turismo Sostenible". Madrid: Ediciones MundiPrensa.

Pollock, A. (2015). Social entrepreneurship in tourism: The conscious travel approach. Tourism Innovation Partnership for Social Entrepreneurship. Recuperado el 20 de julio de 2019 de: https://www.tipse.org/conscious-tourism-pdf-download

Porter, B. A., Orams, M. B., \& Lück, M. (2015). Surf-riding tourism in coastal fishing communities: A comparative case study of two projects from the Philippines. Ocean \& Coastal Management, 116, 169-176. https://doi.org/10.1016/j.ocecoaman.2015.07.015 
Purvis, B., Mao, Y., \& Robinson, D. (2019). Three pillars of sustainability: in search of conceptual origins. Sustainability Science, 14(3), 681-695. https://doi.org/10.1007/s11625-018-0627-5

Rivera, M. y Rodriguez, L. (Coord.) (2012). Turismo responsable, sostenibilidad y desarrollo local comunitario. Córdoba, España: Universidad de Córdoba.

Rivera, M. (2012). Turismo responsable y relaciones interculturales en el contexto de la globalización. En: Interculturalidad: un enfoque interdisciplinar / coord. por L. Rodríguez y A.R. Roldán (pp.181-205). Córdoba, España: Universidad de Córdoba.

Rodríguez J. G., Martínez C. C., y Martín F. R., (2018). Identificación de los factores influyentes en la estrategia de crecimiento de Villa Clara, Cuba a partir del análisis del ciclo de vida del destino turístico. Transitare, 4 (2), 27-47. ISSN: 2395-9835.

Rueda L. A. (2003). Hacia un Turismo Sostenible en los Cayos de Cuba ¿Realidad o Utopía? Caso de Estudio: Hotel La Laguna, Cayo Coco. Arquitectura y Urbanismo, 14(1), 54-59.

Ruiz-Ballesteros, E. (2011). Social-ecological resilience and community-based tourism: An approach from Agua Blanca, Ecuador. Tourism Management, 32(3), 655-666.

Vera-Rebollo, J. F. (2001). Planificación y gestión del desarrollo turístico sostenible: propuestas para la creación de un sistema de indicadores. Universidad de Alicante. ISSN: 1578-679-X.

Vilamajó, D., Vales, M., Capote, R. P., Salabarría, D., \& Menéndez, J. M. (2002). Estrategia nacional para la diversidad biológica y plan de acción en la República de Cuba. La Habana: Editorial Academia, La Habana, 88. 